\title{
Studying Microscopic Peer-to-Peer Communication Patterns
}

\author{
Peter A. Gloor \\ MIT Sloan School of Management \\ pgloor@mit.edu \\ Johannes Putzke \\ University of Cologne \\ putzke@wim.uni-koeln.de \\ Detlef Schoder \\ University of Cologne \\ schoder@wim.uni-koeln.de \\ Taemie J. Kim \\ MIT Media Laboratory \\ taemie@media.mit.edu \\ Akshay Mohan \\ MIT Media Laboratory \\ amohan@media.mit.edu \\ Alex (Sandy) Pentland \\ MIT Media Laboratory \\ pentland@media.mit.edu
}

\author{
Daniel Oster \\ University of Cologne \\ oster@casna.de \\ Kai Fischbach \\ University of Cologne \\ fischbach@wim.uni-koeln.de \\ Koji Ara \\ Hitachi Advanced Research Laboratory \\ k_ara@media.mit.edu \\ Robert Laubacher \\ MIT Sloan School of Management \\ rjl@mit.edu \\ Daniel Olguin Olguin \\ MIT Media Laboratory \\ dolguin@media.mit.edu \\ Benjamin N. Waber \\ MIT Media Laboratory \\ bwaber@media.mit.edu
}

\section{ABSTRACT}

This paper describes first results of an ongoing research effort using real time data collected by social badges to correlate temporal changes in social interaction patterns with performance of individual actors and groups. Towards that goal we analyzed social interaction among a team of employees at a bank in Germany, and developed a set of interventions for more efficient collaboration. In particular, we were able to identify typical meeting patterns, and to distinguish between creative and high-executing knowledge work based on the interaction pattern.

\section{Keywords (Required)}

social networks, social badges, organizational behavior, communication flow, network structure

\section{INTRODUCTION}

Thanks to satellite-controlled Global Positioning Systems (GPS), geographical navigation has become much simpler. A GPS in the car will even influence our future driving behavior, by telling us about traffic jams and directing us to take alternate routes. Unfortunately, until now no such systems exist for the much thornier task of social navigation. As a newcomer in a group, company, or community one has no way of knowing who knows whom, likes whom, wants to collaborate, etc.

The increased prevalence of group work in organizations today creates a need to closer examination of the relationship between structural properties of groups and performance (Cummings \& Cross, 2003). Up to now, only a few studies (e.g. Sparrowe et al., 2001; Reagans \& Zuckerman, 2001; Cummings, 2004; Balkundi \& Harrison 2006) have empirically linked structural properties of a network to the performance of that collective (Cummings and Cross, 2003). Also Balkundi and Harrison (2006) emphasize that we still do not know much about how internal configurations of social networks might facilitate (or inhibit) team efficiency, despite the results they obtained in their meta-analysis. Furthermore, although recent studies employing social network analysis make a significant contribution, they also have a number of weaknesses (for more details, see the literature review in the next section). In part, these shortcomings stem from the type of interaction being analyzed: For good reasons the mining of electronic interaction archives has become a widely used tool for analyzing communication networks. While this approach has provided important insights into how organizations function and what 
management practices lead to greater productivity, a large number of important organizational communications are face-toface, so studies based on mining electronic interactions are missing a great part of the picture.

In this research project, we develop an alternative method to map social interaction. Using a new type of body-worn sensor networks - 'social badges' - we are able to trace who talks to whom, and even how they talk to each other (Olguin Olguin et al. 2007).

The remainder of the article is structured as follows: The next section is an in-depth literature review of work linking social network analysis and group performance. Next, we highlight some weaknesses of existing studies and the methodologies employed. In the next section we propose a new methodology to overcome these shortcomings. Preliminary results of a case study employing the new methodology are then described. The final section discusses the new methodology and the preliminary study findings, addressing their theoretical and managerial implications, limitations, and possible directions for future research.

\section{LITERATURE REVIEW}

The term social network denotes the social structure that emerges from human actors' interaction with each other. Over the years, various disciplines have proposed different methods and techniques to discover these structures and to allow inferences about functioning of social networks. These methods and techniques are generally summarized under the term social network analysis (SNA) (Wasserman \& Faust, 1994). The roots of SNA lie in anthropology, sociology, psychology and organizational theory. Whereas social network analysis has been applied in the aforementioned disciplines for more than six decades, there has been over the past few years a boom of interest in network research management science, due to a general shift away from individualist, essentialist and atomistic explanations toward more systematic, contextual and relational understandings (Borgatti \& Foster 2003). The relationship between network structure and organizational and individual performance has emerged as an important focus of this research. This is understandable, because in a society based on the division of labour, an actor's performance depends to a large extent on the other actors he/she has to cooperate with (Brass et al. 2004). This holds particularly true for jobs that require acquisition or master of large amounts of information, or reconfiguration of information in novel ways (cf. Perry-Smith \& Shalley, 2003).

In this literature review, we focus on prior research examining the relationship between network structure, communication behaviour, and performance of work groups (cf. Katz et al. 2004). Although this topic has been on the research agenda for more than 50 years (e.g. Bavelas, 1950; Guetzkow \& Simon, 1955; Leavitt, 1951; Shaw, 1964), only few studies dealt with the topic during the $60 \mathrm{~s}$ and $70 \mathrm{~s}$. Consequently most of these early studies became subject to "academic amnesia", because they were conducted before current researchers and their mentors were trained (Balkundi \& Harrison, 2006, p.49). Nevertheless, Granovetter's (1985) work about the embeddedness of individuals in social networks initiated a revival of social network analysis in management theory and research. Furthermore, the increasing formalization and quantification of social network analysis, as well as the wide availability of computing power, fostered works that examined the relationship between social network structure and group performance (for a review see Borgatti \& Foster 2003).

Consequently, much recent work has examined the relationship between quantitative measures on group performance. The two most common measures employed in this kind of analysis are centrality (e.g. Baldwin et al., 1997; Balkundi \& Harrison, 2006; Brass, 1981; Tsai, 2001), and density (e.g. Balkundi \& Harrison, 2006; Mayo \& Pastor, 2005; Reagans \& Zuckerman, 2001; Reagans et al., 2004; Sparrowe et al., 2001). From the different centrality measures, in-degree centrality is the most often used centrality measure (Balkundi and Harrison (2006). In their analysis many authors acknowledge that different types of social networks might have different effects on actors' performance. Therefore, many authors specify the social networks under examination either as friendship/advice-networks (e.g. Baldwin et al., 1997; Balkundi \& Harrison, 2006; Bond et al., 2004; Moran 2005), hindrance-networks (e.g. Sparrowe et al. 2001) or task-networks (e.g. Mayo and Pastor, 2005).

Despite these distinctions, however, many findings from these studies have conflicted. For example, concerning the relationship between centrality and performance, Levi et al. (1954) find that a higher centrality among group leaders enhances group performance. Also Balkundi and Harrison (2006) find in their meta-analysis that teams with central leaders in the intra-team network perform better, as well as teams that are more central in the inter-group network. A theoretical underpinning for this kind of relationship is that a higher centrality provides access to relevant resources.

On the other hand, some authors obtained results that showed the opposite. For example, Boyd \& Taylor (1998) state that a higher centrality of group leaders results in a lower performance because of the high costs associated with maintaining many relationships. Also Sparrowe et al. (2001) find a negative relationship between advice network centrality and group performance, consistent with the findings of other experimental research conducted in the 1950s (cf. Shaw 1964). As theoretical underpinning for their hypotheses, Sparrowe et al. (2001) use Molm's (1994) distinction between dependence, 
independence, and interdependence: where actors in interdependent networks share control over joint outcomes, actors in dependent relationships can gain at the expense of others without contributing to their production. Actors in decentralized networks are supposed to be more interdependent, which encourages cooperation. Sparrow et al. (2001) results provide evidence for Molm's (1994) statement that it is not sufficient to look at the performance of each member's individual performance to assess the performance of a work group. To be precise, Sparrow et al. (2001) find that an actor's individual job performance is positively related to centrality in advice networks and negatively related to centrality in hindrance networks.

Concerning the relationship between density and performance, Reagans and Zuckerman (2001) state that a higher density in a group network leads to higher performance. Also Balkundi and Harrison (2006) find in their meta-analysis that teams with denser expressive and instrumental social networks tend to remain more viable and to perform better. The theoretical reasoning is similar to the explanation given above: The transmission of task-related knowledge and tacit knowledge might be more difficult in low density work groups (Hansen, 1999). The members in a high density advice network might benefit from greater cooperation, greater information sharing, a stronger sense of accountability, greater agreement on expectations, and less tendency to engage in social loafing (Sparrowe et al. 2001). A larger percentage of group members exchanging advice indicate a greater mutual interdependence (Sparrowe et al., 2001) which fosters cooperation and leads to a higher group performance (Molm, 1994). On the other hand, Sparrowe et al. (2001) cannot support the hypothesis that advice network density is positively related to group performance, although they find that hindrance network density is negatively related to group performance. A reason might be that the high costs of maintaining high density work groups might lead to lower performance (Burt, 1997).

Although all aforementioned studies make significant contributions, they are still hampered by one or more of the following four methodological weaknesses: First, in most studies the social network is reconstructed out of surveys. In doing so, the researchers question all actors about their relationship to each other. Afterward, the corresponding connections between actors are derived by the researchers by hand and entered in social network analysis software packages such as UCINET. However, this procedure can only reflect a part of the actors' real communication behavior. Furthermore it is subject to biases such as social desirability or media disruption/discontinuity. Second, most studies about teams have so far neglected temporal aspects in their analysis (Balkundi and Harrison, 2006). Although there exist theories about networks and time (Kilduff \& Tsai, 2003) and teams and time (Gersick 1988), there is no comprehensive theory about the interplay of networks, team processes and team outcomes over time (Balkundi and Harrison, 2006). Third, many studies neglect alternative new ways of communication. For example, there is still a remarkable gap in research whether an actor's position in an e-mail network or telephone network reflects his position in the face-to-face network (cf. Wellman 2001, Grippa et al. 2006). Fourth, the proposed methodologies often cannot be applied at scale for large organizations.

Our approach — using social badges that automatically collect data on interactions-addresses these shortcomings by providing a new and richer method to capture the interaction of peers in a social network.

\section{OUR APPROACH}

In a long term project, MIT's Center for Collective Intelligence (formerly Center for Coordination Science) has identified interaction patterns of successful teams and organizations through dynamic social network analysis (DSNA). This work has correlated performance metrics such as revenue, productivity, peer ratings, and customer satisfaction with social network metrics in a variety of settings, including, for example, Eclipse open source programmers (Kidane \& Gloor 2005). Another project compared the social networks comprised of face-to-face interactions, as revealed by survey data, versus the networks surfaced through mining of e-mail archives (Grippa et. al. 2006).

In this project we are using social badges developed at the MIT Media Laboratory (for a technical description cf. Olguin Olguin et al. 2007), which allow us to measure the relative location and behavioral characteristics - such as gestures and tone of voice - of their wearers. The social badges combine infrared sensor interaction, Bluetooth location measurement, measurement of body movement by accelerometer, and voice and pitch detection. We construct social networks by collecting location and directionality of the wearers' interactions. To analyze the social networks, we use our Condor software tool, formerly known as TeCFlow, which generates dynamic visualizations of social networks by mining communication archives such as e-mail, phone logs, and blogs (Gloor and Zhao 2006).

We conducted a dynamic social network analysis by collecting social badge interaction data from one department of a bank over a period of four weeks. We also collected e-mail data from the bank employees. We also administered a daily online survey to the study subjects collecting their daily assessment of their productivity and satisfaction with their own work. Furthermore we collected performance indicators such as achievement of objectives, benchmarking of tasks, personal evaluation, and self-assessment on the group and individual level. 
A central question addressed in this paper is how communication and social network structure influence individual and group performance. As a result of the dynamic social network analysis, we were able to identify different categories of communication patterns typical of managers as well as of creative and more repetitive tasks. We also were able to find efficient communication patterns for common tasks such as managing meetings.

\section{DIFFERENCES IN FACE-TO-FACE AND E-MAIL NETWORKS}

In this research we analyze the social network of a department at a bank comprising 22 people organized in 4 teams: development, sales, customer service, and support. Figure 1 illustrates the e-mail network of the 22 people. Size of the nodes representing actors depicts their degree centrality. As figure 1 illustrates, management is surprisingly peripheral in the e-mail network. The most central person is the department's secretary, shown as the large node labeled "Support" in the center of the graph.

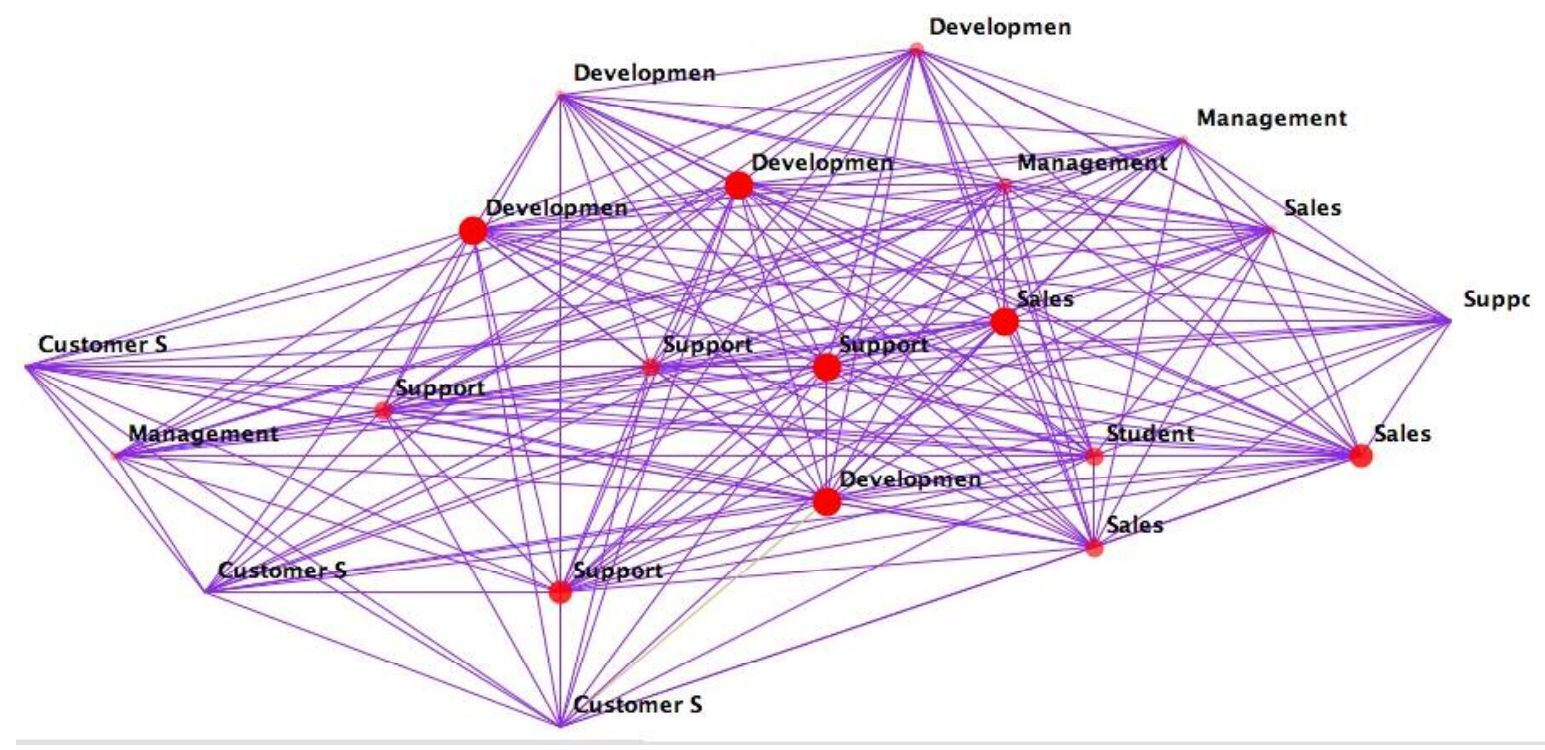

Figure 1. E-Mail interaction network over one month of 22 people bank department

Figure 2 shows the face-to-face interaction network, recorded by the infrared sensors in the social badges. Size of a node depicts betweeness centrality of the actor. As figure 2 illustrates, the department head is the most between actor, labeled "Management" in the center of the graph. The second most between actor is an employee labeled "Sales" to the left of the department head. 


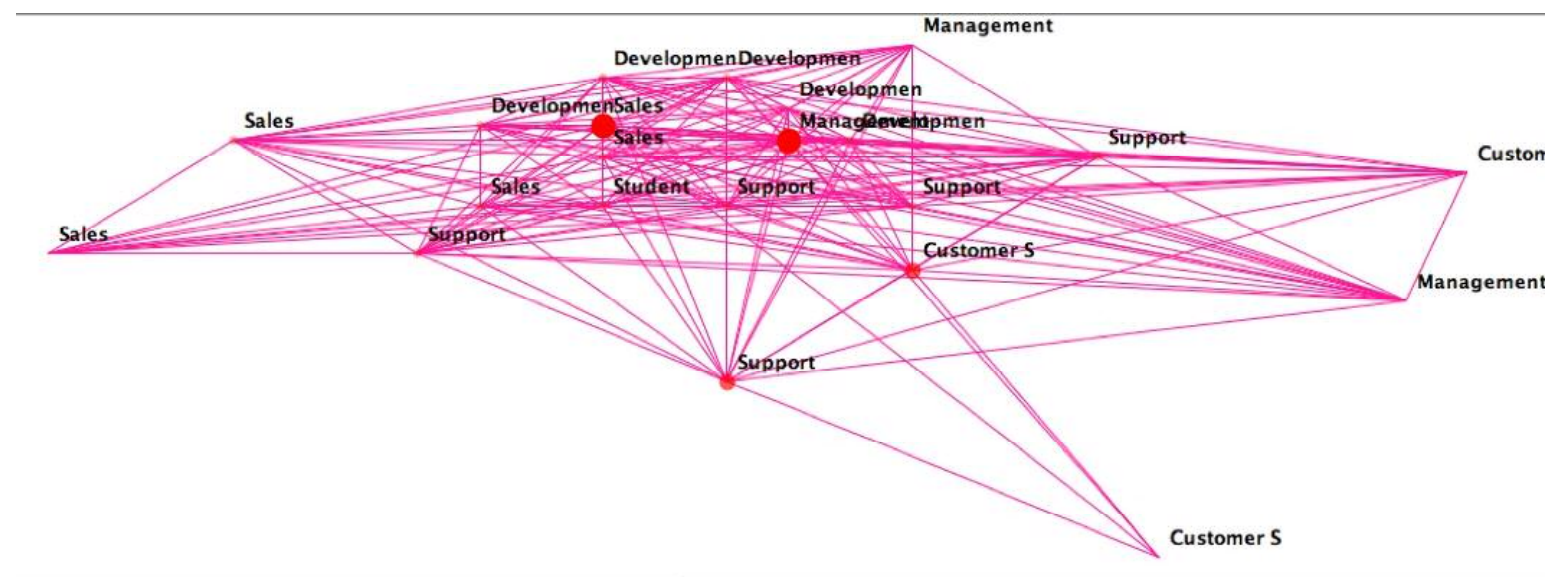

Figure 2. Face-to-face network, collected through IR sensor interaction

As figures 1 and 2 illustrate, there are substantial differences between the e-mail and face-to-face interaction network. There are people who are highly central in the e-mail network, but peripheral in the face-to-face network, and the other way round. Note for example the peripheral position of the customer service representative at the lower right in the face-to-face network in figure 2. Interestingly, the e-mail network is more cohesive, there are no such outliers as in the face-to-face interaction network. We can speculate that this might also be because the secretary and the managers send cc-messages to all employees, therefore integrating otherwise isolated employees into the information flow of the department.

Combining the e-mail and face-to-face network leads to a more complete depiction of collaborative relationships. As figure 3 illustrates, there is a core cluster of well-connected people (the large red circle). The department head is right in the center of this cluster. The department is split into two sections (with this split indicated by the red dotted line), one consisting of the support and customer services team members, the other of the sales and development team members. The customer services team is separated from the rest of the department, with the support team members acting as gatekeepers. The sales and development team are well integrated. Both parts of the department include a core group (blue circles), on the one side made up by the support team, on the other side consisting of the core development and sales team members. Interestingly, the two other managers besides the department head are quite peripheral.

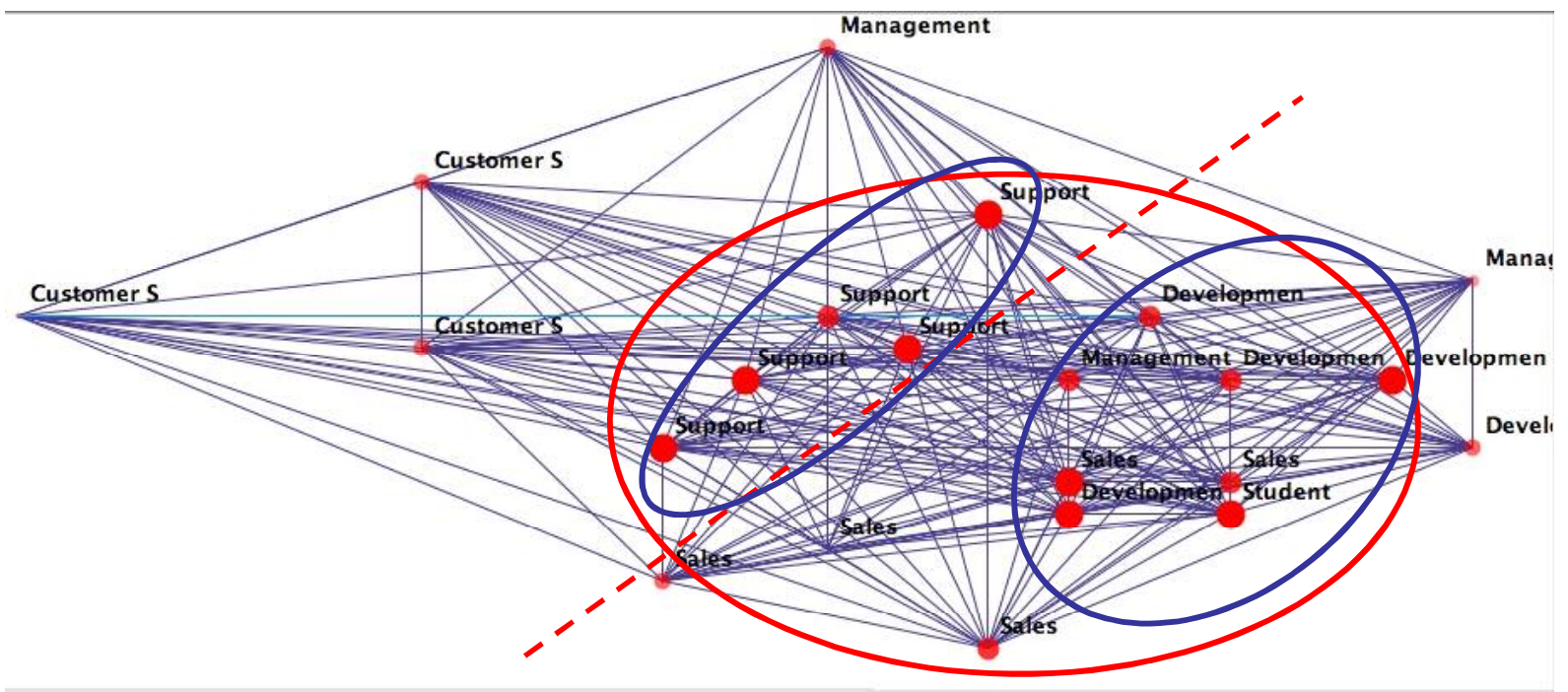

Figure 3. Combined social network of 22 people department over one month 
Figure 3 gives a complete overview of the social network of the department, derived from objective data about actual communication interactions. Until now, such a network would have either to be constructed using e-mail analysis, leading, as we have shown here,to the misleading network structure in figure 1, or it would have been constructed using a survey, with all the problems inherent in self-reporting, such as biases due to social desirability.

\section{ZOOMING IN ON ACTIVITIES}

Snapshots of the IR interaction network give an indication of what is going on in the course of a day. Figure 4 illustrates the social network at 4 points in time at one day. Activities of teams have been identified by mapping time stamps of interaction records to entries in the group Lotus Notes calendar. The top left picture in figure 4 illustrates informal social interaction among members of different teams in the morning. A line indicates two people talking to each other in the same time window, set to 30 minutes for this picture. The bottom left picture shows the social network structure of 8 people participating in a meeting. The picture illustrates that within 30 minutes, there were 8 people talking and spoken to, with 65 being the most active participant, followed by 92 and 49.65 and 92 were talking to each other a lot (depicted by a short connecting line), as were 49 and 94 . At the same time, 64 and 90 were also talking to each other, most likely in another room. The top right picture shows one-on-one interaction at lunch of people sitting opposite each other at the table and talking to each other. The bottom right shows a non-planned meeting of 7 people, with 49 being the most central person.

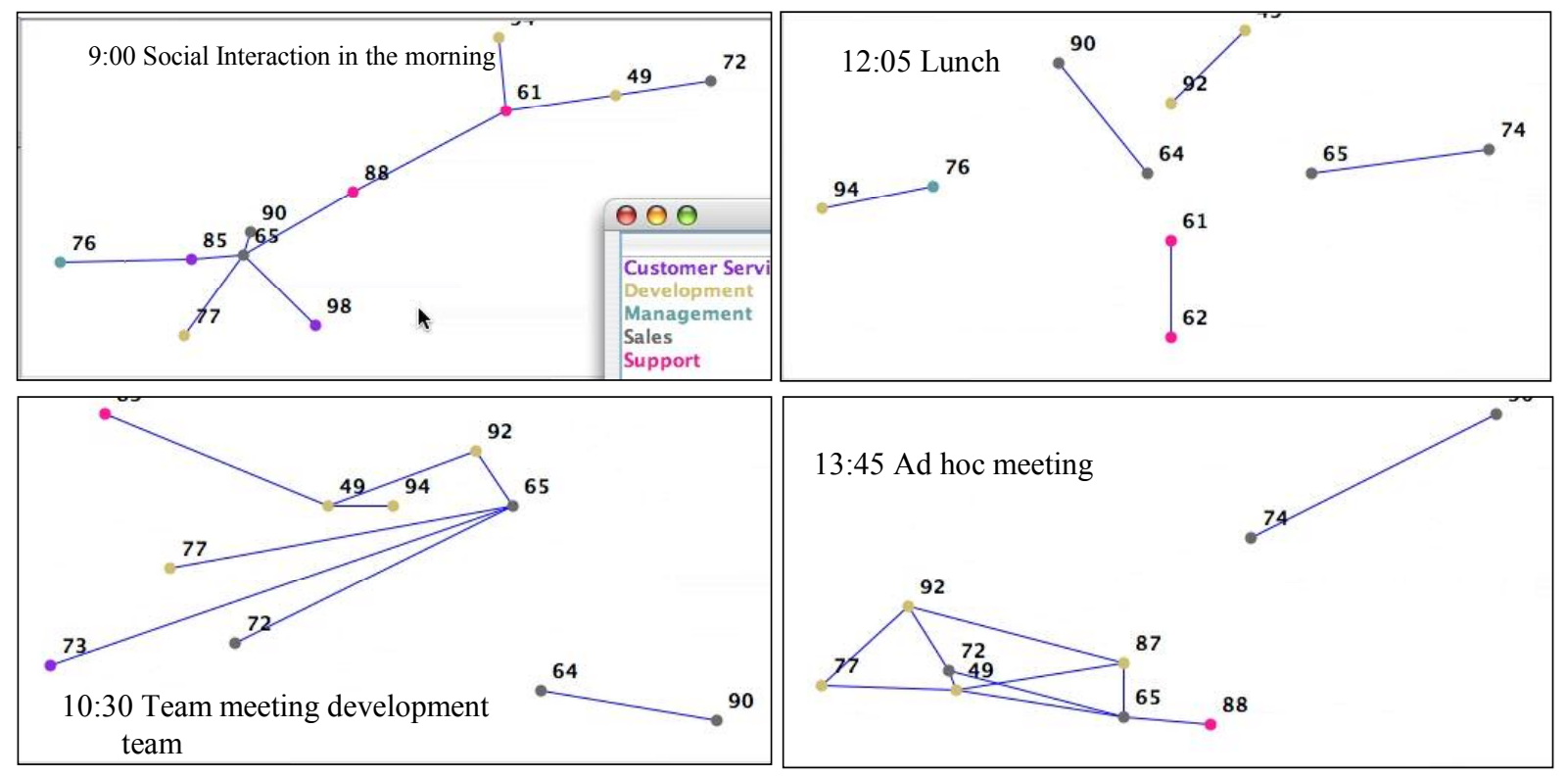

Figure 4. One day in the life of department $X$

Figure 5 illustrates the group dynamics of the monthly department meeting. The $\mathrm{X}$-axis of figure 5 shows time in minutes, again with a time window of 30 minutes. The $\mathrm{Y}$-axis shows individual actors, and the Z-axis shows betweeness centrality of the individual actors at any given point in time. 


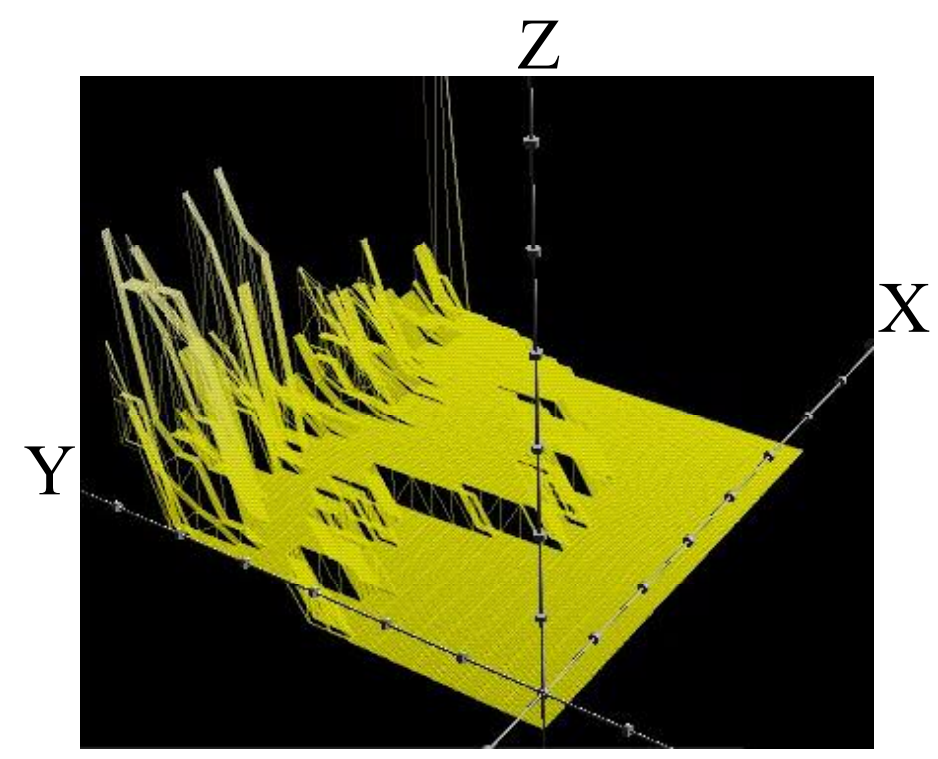

Figure 5. Temporal Social Surface of an "all hands" department meeting

As figure 5 illustrates, the department meeting is happening in a quite democratic way, with strong fluctuations in beweeness centrality, and with different group sizes of active people. Phases of centralized control, where a few people control interactions with high centrality, alternate with phases of wide group activity, where many team members interact with each other with low betweeness centrality. As we have shown in an earlier study (Kidane \& Gloor, 2006), such communication patterns are indicative of creative work.

\section{IDENTIFYING CREATIVE AND HIGH-EXECUTING ACTORS AND TEAMS}

In prior work (Kidane \& Gloor, 2006) we have found a clear separation between high performing and highly creative knowledge workers: high creativity of an actor correlates with fluctuating betweeness centrality over time, high performance correlates with steady betweeness centrality. In other words, a team with a stable communication structure is better suited for high-executing, more repetitive tasks, while a team where communication structures change continuously is better suited for creative work.

Figure 6 illustrates that department members display widely different communication patterns. The betweeness curves of the actor in the top left window with strong fluctuations both in e-mail and face-to-face interaction indicate creative activities, the steady pattern of the actor in the lower right window is indicative of a person communicating very little in a continuous way, most likely in a more repetitive high-executing type of role. Looking at all 22 communication patterns permitted us to make a separation between "high executors" and "creatives". Interestingly, this separation corresponded well with the split of the department into the high-executing top half of figure 3 , and the creative bottom half of the department in figure 3 . 

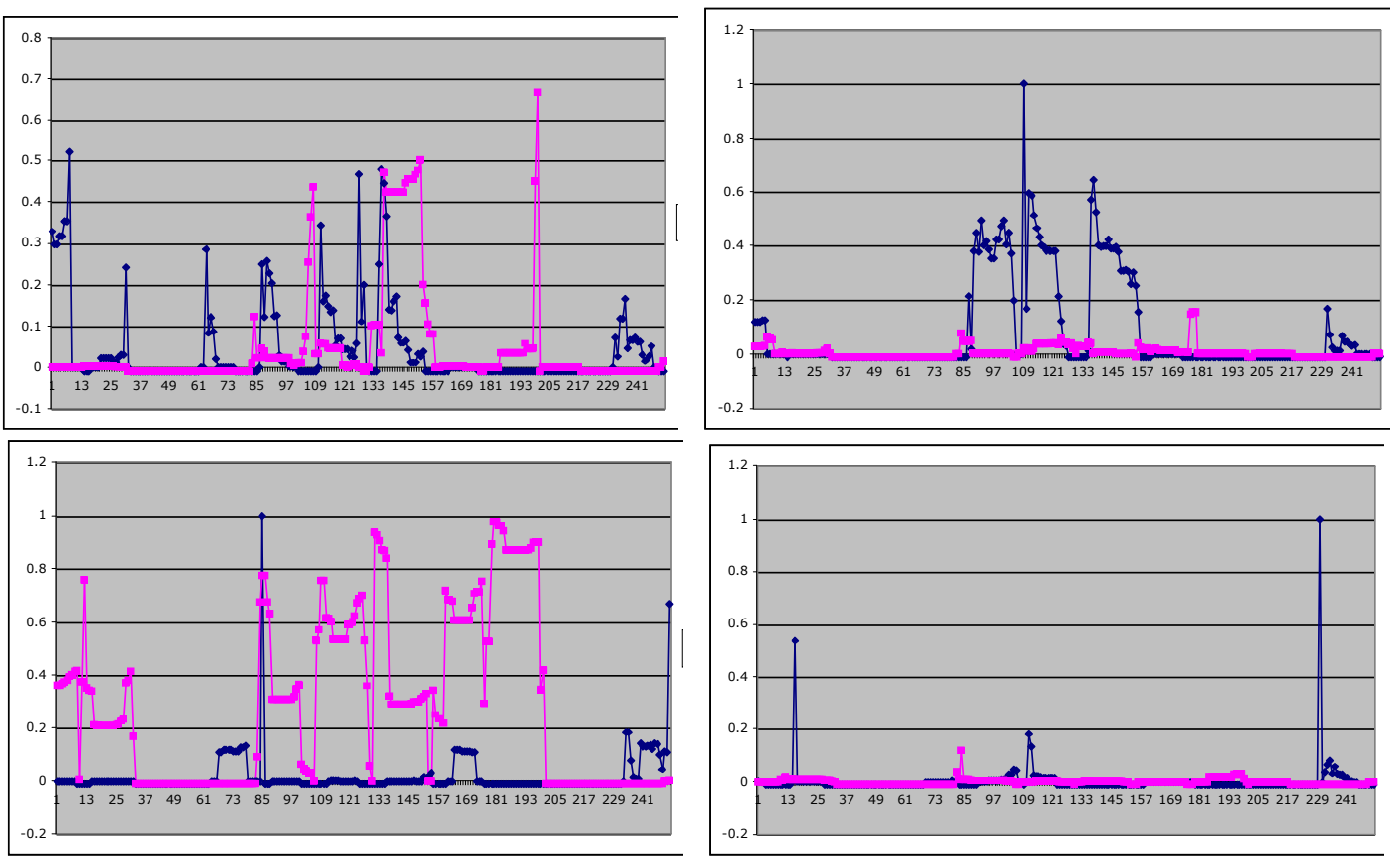

Figure 6. Top left actor has fluctuating e-mail and face-to-face interaction, top right actor has fluctuating face-to-face, but steady e-mail interaction, bottom left actor has steady face-to-face, but fluctuating e-mail interaction, bottom right actor as steady face-to-face and e-mail interaction (blue line: betweeness over time of actor's face-to-face interaction, measured by IR, purple line: betweeness over time of actor's e-mail interaction) (x-axis: time in hours, $\mathrm{y}$-axis: betweenness)

We can repeat the same analysis we did for the individual actors on the group level. Teams have now been condensed into one virtual actor by combining the actors of each team into one social network node. Figure 7 shows communication between different teams on the condensed team level. The development and the sales team are communicating the most with each other, management communicates most with the development, and then with the sales and support team.

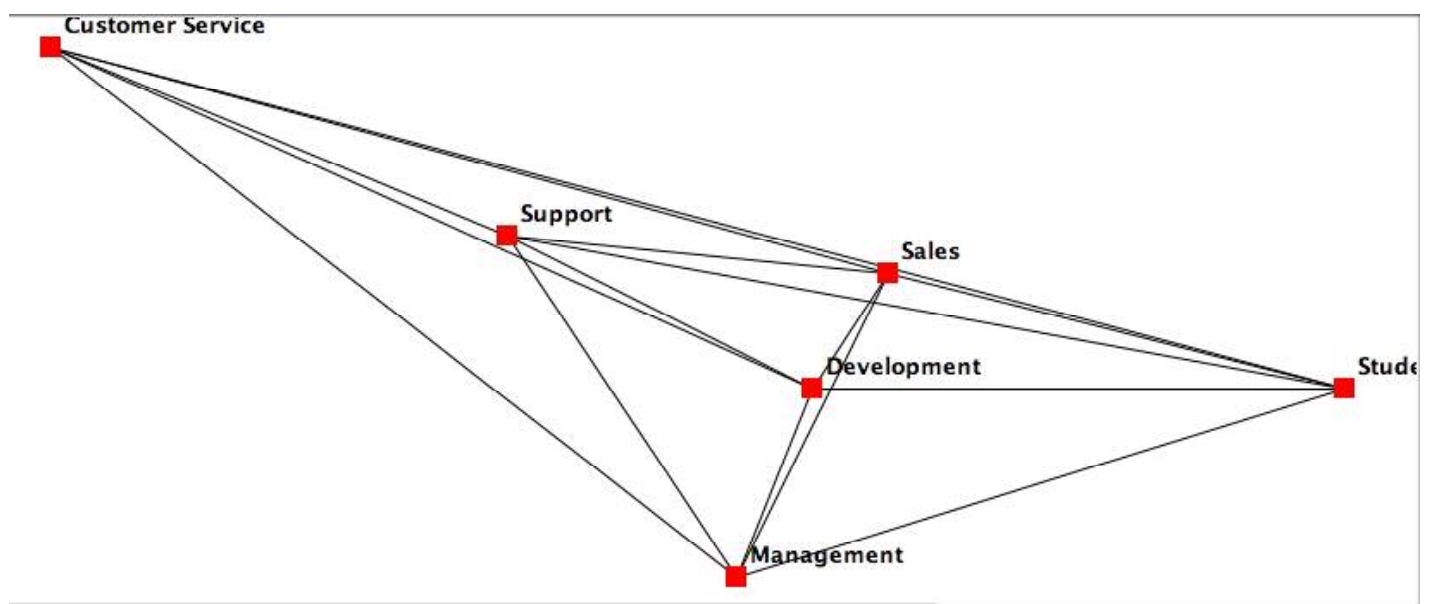

Figure 7. Communication between different teams 
Looking at the changes in betweeness centrality over time, we can clearly distinguish between "high executing" and "creative" teams. Figure 8 shows the fluctuations in betweeness of 4 teams on the team level, i.e. with the 6 virtual actors of figure 7, taken with Condor with a time window of 30 minutes.
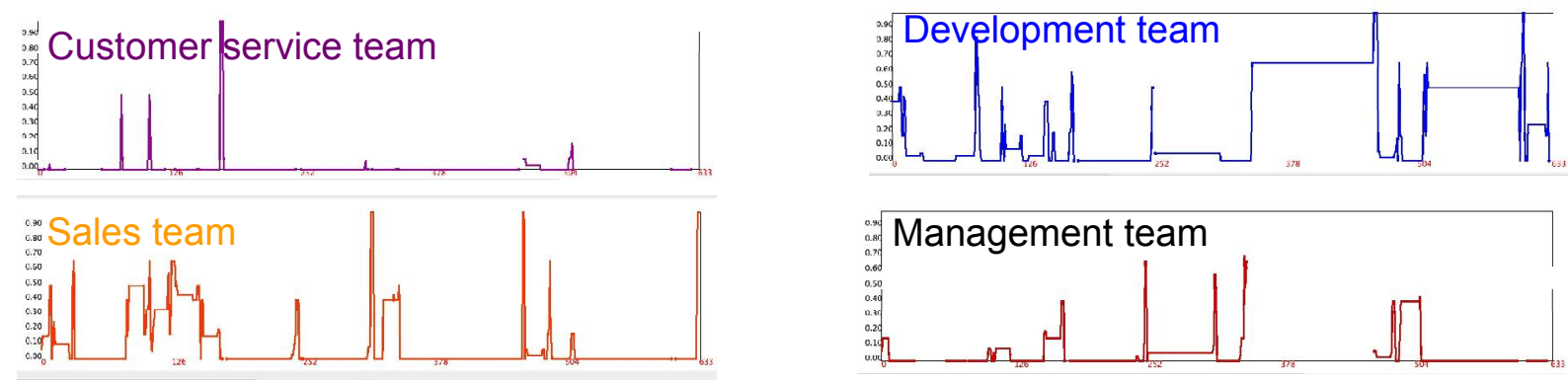

\section{high oscillation $=$ high creativity low oscillation $=$ high performing}

Figure 8. Fluctuations in betweeness centrality of teams

As figure 8 illustrates, we get confirmation of the split of the department into creatives and high-executors as shown in figure 3. Individual team members with a "creativity pattern" work in creative teams, team members with a high-executing communication pattern work in high-executing teams. The customer service team, having the repetitive task of processing new contracts, is the most high-executing, with a steady communication pattern with little change over the observation period of 30 days. This is in contrast to the highly fluctuating communication patterns of the sales and development teams, which are responsible for planning Web marketing campaigns and planning and developing the corporate Web site. Management also displays a creativity pattern, although less accentuated than that of the sales and development teams.

\section{SUMMARY AND DISCUSSION}

In the literature review in section 2 we identified four major methodological weaknesses of previous studies. Our approach addresses these weaknesses as follows: First, the social network used for analysis was constructed by using social badges, which allow statements about the face-to-face communication behavior between actors. In doing so, biases due to social desirability or media disruption can be avoided. Second, we took into account temporal aspects of network formation/performance by conducting a longitudinal study. Furthermore, we used a novel software tool, TeCFlow/Condor that allows for dynamic analysis of network formation. Third, the inclusion of social badges allows for comparisons between different types of communication networks (e.g. face-to-face network, e-mail network, telephone network). Fourth, the developed software is adequate to conduct analysis on the whole organizational level, particularly if e-mail archives are used as data input (though the analysis in this study was undertaken in a department with a few dozen members, and not in an entire enterprise with thousands of members).

As with any empirical study that makes use of social network analysis, this work is subject to limitations. First, the study does not try to answer certain questions of causality. We cannot discern whether certain social structures within teams lead to an improved team performance, or whether better performance induces certain social structures. Meta-analytic data as well as theory, however, show that integrative network structures are more strongly positioned as antecedents to team performance rather than as by-products of it (Balkundi and Harrison 2006). A second limitation is that the study was a field study and not conducted as a laboratory experiment. On the one hand, there are indications that the impact of integrative social structure on team task performance weakens over time and team members become more familiar with each other. In the end, familiarity might even neutralize network effects (Balkundi and Harrison, 2006). Since team members in the study were very familiar to each other, this might bias our results. 
Our study contributes to research on social network analysis and group performance by giving insights to practitioners involved in decisions about team composition. Up to now, managers often used demographic characteristics as their basis of decision making. However, Reagans and Zuckerman (2004) compare the social network approach vs. the demographic approach for evaluating the potential of a work group. They find that these approaches are not interchangeable, although homophily theory suggests that actors with similar demographic characteristics build similar networks.

Our preliminary study findings suggest that the e-mail network does not reflect the communication behavior within an organization. This confirms our earlier research in an Italian research lab (Grippa et al 2006), where e-mail and face-to-face interaction was negatively correlated. This is contradictory to Wellman (2001) who found that e-mail communication is a sufficiently good approximation for the real communication behavior inside an enterprise. Future research should examine the properties of different kinds of communication networks (e.g. face-to-face network vs. e-mail network) inside enterprises in more detail.

The study findings might also provide useful insights to related research in psychology examining the relationship between group cohesion and group performance (e.g. Beal et al., 2003; Mullen and Cooper 1994) or how group goals might influence group performance (O'Leary-Kelly et al. 1994).

This paper describes first results of a project aiming to identify high-performing interaction patterns of knowledge workers by measuring social interaction at the microscopic level. The study illustrated the use of social badges in several work groups in a bank. Analyzing the face-to-face network is a more objective way of doing social network analysis, which enables identification of hidden gatekeepers, connectors, and influentials. The long-term goal of our research is to develop a set of interventions and recommendations that can lead to better individual and group performance. Towards that goal, this study and its proposed methodology can help to obtain generalizable insights about the relationship between social network and performance. We hope that research projects like ours will assist others in conducting this kind of study and form the basis for substantial future research dealing with social networks or performance of individuals, groups and/or organizations.

\section{REFERENCES}

Baldwin, T.T., Bedell, M.D. \& J.L. Johnson (1997) "The Social Fabric of a Team-Based M.B.A. Program: Network Effects on Student Satisfaction and Performance", Academy of Management Journal, 40(6), pp. 1369-1397.

Balkundi, P. \& D.A. Harrison (2006) "Ties, Leaders, and Time in Teams: Strong Inference About Network Structure's Effects on Team Viability and Performance", Academy of Management Journal, 49(1), pp. 49-68.

Bavelas, A. (1950) "Communication Patterns in Task-Oriented Groups", Journal of Acoustical Society of America, 22, pp. 725-730.

Beal, D.J., Cohen, R.R., Burke, M.J. \& C.L. McLendon (2003) "Cohesion and Performance in Groups: A Meta-Analytic Clarification of Construct Relations", Journal of Applied Psychology, 88, pp. 989-1004.

Bond, E.U., Walker, B.A., Hutt, M.D. \& P.H. Reingen (2004) "Reputational Effectiveness in Cross-Functional Working Relationships", Journal of Product Innovation Management, 21, pp. 44-60.

Borgatti, S.P. \& P.C. Foster (2003) "The Network Paradigm in Organizational Research: A Review and Typology", Journal of Management, 29(6), pp. 991-1013.

Boyd, N.G. \& R.R. Taylor (1998) "A Developmental Approach to the Examination of Friendship in Leader-Follower Relationships", Leadership Quarterly, 9, pp. 1-25.

Brass, D.J. (1981) "Structural Relationships, Job Characteristics, and Worker Satisfaction and Performance", Administrative Science Quarterly, 26(3), pp. 331-348.

Brass, D.J., Galaskiewicz, J., Greve, H.R. \& W. Tsai (2004) "Taking Stock of Networks and Organizations: A Multilevel Perspective", Academy of Management Journal, 47(6), pp. 795-817.

Burt, R.S. (1997) "The contingent value of social capital", Administrative Science Quarterly, 42, pp. 339-365.

Cummings, J.N. (2004) "Work Groups, Structural Diversity, and Knowledge Sharing in a Global Organization", Management Science, 50(3), pp. 352-364.

Cummings, J.N. \& R. Cross (2003) "Structural Properties of Work Groups and their Consequences for Performance", Social Networks 25, pp. 197-210.

Gersick, C. (1988) "Time and transition in work teams: Toward a new model of group development", Academy of Management Journal, 31, pp. 9-41. 
Gloor, Peter. Capturing Team Dynamics Through Temporal Social Surfaces, Proceedings of 9th International Conference on Information Visualisation IV05, London, 6-8 July 2005.

Gloor, Peter and Yan Zhao. TeCFlow - A Temporal Communication Flow Visualizer for Social Networks Analysis, ACM CSCW Workshop on Social Networks. ACM CSCW Conference, Chicago, Nov. 6. 2004.

Grippa, Francesca, Antonio Zilli, Robert Laubacher, and Peter Gloor. E-mail May Not Reflect The Social Network, NAACSOS Conference, June 22 - 23, Notre Dame IN, North American Association for Computational Social and Organizational Science, 2006.

Granovetter, M. (1985) "Economic Action and Social Structure: The Problem of Embeddedness", American Journal of Sociology, 91(3), pp. 481-510.

Guetzkow, H. \& H. Simon (1955) "The Impact of Certain Communication Nets Upon Organization and Performance in Task-Oriented Groups", Management Science, 1, pp. 233-250.

Hansen, M. (1999) "The Search-Transfer Problem: The Role of Weak Ties in Sharing Knowledge Across Organizational Subunits", Administrative Science Quarterly, 44, pp. 82-111.

Katz, N., Lazer, D., Arrow, H. \& N. Contractor (2004) "Network Theory and Small Groups" Small Group Research, 35(3), pp. 307-332.

Kidane, Y. Gloor, P. Correlating Temporal Communication Patterns of the Eclipse Open Source Community with Performance and Creativity. Computational and Mathematical Organization Theory, Springer, Volume 13, Issue 1, March 2007.

Kilduff, M. \& W. Tsai (2003) Social Networks and Organizations, London: Sage.

Leavitt, H. (1951) "Some Effects of Certain Communication Patterns on Group Performance", Journal of Abnormal and Social Psychology, 46, pp. 38-50.

Levi, M., Torrance, P.E. \& O.G. Pletts (1954) "Sociometric Studies of Combat Air Crews in Survival Training", Sociometry, 17 , pp. 304-328.

Mayo, E. (1933) "The Human Problems of an Industrial Civilization", New York: Macmillan Press.

Mayo, M. \& J.C. Pastor (2005) Networks and Effectiveness in Work Teams: The Impact of Diversity, Working Paper WP0510, Madrid: IE Business School.

Molm, L.D. (1994) "Dependence and Risk: Transforming and Structure of Social Exchange. Social Psychology Quarterly, 57, pp. 163-176.

Moran, P. (2005) "Structural vs. Relational Embeddednness: Social Capital and Managerial Performance", Strategic Management Journal, 26, pp. 1129-1151.

Mullen, B. \& C. Copper (1994) "The relation between group cohesion and performance: An integration", Psychological Bulletin, 115, pp. 210-227.

O'Leary-Kelly, A.M., Martocchio, J.J. \& D.D. Frink (1994) "A Review of the Influence of Group Goals on Group Performance", Academy of Management Journal, 37, pp. 1285-1301.

Olguin Olguin, D., Waber, B.N., Kim, T., Mohan, A., Ara, K. \& A. Pentland (2007) "Sensible Organizations: Technology and Methodology for Automatically Measuring Organizational Behavior ", Working Paper (submitted to IEEE Transactions on Systems, Man, and Cybernetics - Part B: Cybernetics)

Perry-Smith, J.E. \& C.E. Shalley (2003) "The Social Side of Creativity: A Static and Dynamic Social Network Perspective", Academy of Management Review, 28(1), pp. 89-107.

Reagans, R. \& E.W. Zuckerman (2001) "Networks, Diversity, and Productivity: The Social Capital of Corporate R\&D Teams", Organization Science, 12(4), pp. 502- 517.

Reagans, R., Zuckerman, E.W. \& B. McEvily (2004) "How to Make the Team: Social Networks vs. Demography as Criteria for Designing Effective Teams", Administrative Science Quarterly, 49(1), pp. 101-103.

Shaw, M. (1964) "Communication Networks", in: Berkowitz, L. (ed.) Advances in Experimental Social Psychology, New York: Academic Press, pp. 111-147.

Sparrowe, R.T., Liden, R.C. \& S.J. Wayne (2001) "Social Networks and the Performance of Individuals and Groups", Academy of Management Journal, 44(2), pp. 316-326. 
Tsai, W. (2001) "Knowledge Transfer in Intraorganizational Networks: Effects of Network Position and Absorbtive Capacity on Business Unit Innovation and Performance", Academy of Management Journal, 44(5), pp. 996-1005.

Wasserman, S. \& K. Faust (1994) Social Network Analysis: Methods and Applications, New York: Cambridge University Press.

Wellman, B. (2001) "Computer Networks As Social Networks", Science, 293, pp. 2031-2034. 